\title{
Rancang Bangun Penstabil Drone S2GA Berbasis Metode Fuzzy Logic Menggunakan Arduino
}

\section{Design of S2GA Drone Stabilizer Base on Fuzzy Logic Methods Using Arduino}

\author{
Wahyu Pambudi ${ }^{1 *}$, Yudhi Darmawan ${ }^{2}$ Priska Choirina $^{3}$ \\ Jurusan Teknik Telekomunikasi Poltekad Kodiklatad \\ Jalan Ksatrian Pusdik Arhanud, Pendem, Batu 65324 \\ komd4214@gmail.com ${ }^{1 *}$,yudhipk8@gmail.com², Priskachoirina17@gmail.com ${ }^{3}$
}

\begin{abstract}
Abstrak - UAV merupakan wahana teknologi canggih yang sering digunakan di bidang militer untuk misi pengintaian. UAV terdiri dari beragam jenis, salah satunya yaitu quadcopter. Quadcopter yang digunakan dalam misi militer biasanya mempunyai masalah ketidakstabilan ketika quadcopter tersebut terbang membawa senjata. Oleh karena itu, maka diperlukan sebuah sistem untuk mengatur kestabilan dari percepatan motor quadcopter. Pada paper ini dipaparkan sebuah desain system dari stabilizer drone dengan metode logika fuzzy menggunakan 3 derajat. Penelitian ini bertujuan untuk mengkonfigurasikan kontrol kestabilan quadcopter yang optimal setelah diterapkan metode fuzzy logic inferensi Tsukamoto. Input dari system ini adalah percepatan dan perubahan percepatan. Sedangkan output yang dihasilkan berupa kecepatan motor. Untuk mengetahui error dilakukan pengujian ketepatan posisi 5 kali pada ketinggian 1-3 meter. Sedangkan untuk mendapatkan waktu quadcopter untuk kembali ke posisi semula dapat menggunakan stopwatch. Penelitian ini bertujuan untuk mengkonfigurasikan kontrol kestabilan quadcopter yang optimal setelah diterapkan metode fuzzy logic inferensi Tsukamoto. Hasil penelitian dengan logika fuzzy untuk kestabilan menunjukan nilai rise time sebesar 0,7 detik, settling time 2,55 detik, overshoot sebesar $15 \%$ ketika menerima gangguan sebesar $45 \mathrm{~cm}$, dan nilai steady-state $69,55 \mathrm{~cm}$ dengan simpangan baku sebesar $\pm 1,775 \mathrm{~cm}$. Hasil tersebut memberikan akurasi dalam menentukan kestabilan yang lebih baik pada quadcopter.
\end{abstract}

Kata Kunci: UAV, Quadcopter, Kestabilan, Fuzzy Logic, Tsukamoto.

\begin{abstract}
UAV is one of the advanced technology that used in the military for reconnaissance missions. $U A V$ consists of various types, one of them is a quadcopter. Since the quadcopter in military missions has an instability problem when they fly with a weapon, they needed to stabilize the acceleration of a quadcopter motor. This paper presents a design system of drone stabilizer using fuzzy logic method based on 3 degrees of freedom to improve stability. Fuzzy logic that used to configure optimal quadcopter stability control is Tsukamoto's inference fuzzy logic method. The input of this system are acceleration and acceleration change. While, the output of this system is the speed of motor. We did 5 times experiment to find out the accuracy of this system at an altitude of 1-3 meters. Furthermore, to get the quadcopter time from return to its original position we used a stopwatch. Based on the experiments, we obtained a rise time value of 0.7 seconds, settling time of 2.55 seconds, overshoot of $15 \%$ when receiving interference of $45 \mathrm{~cm}$,
\end{abstract}

TELKA, Vol.6, No.2, November 2020, pp. 104 112

ISSN (e): 2540-9123

ISSN (p): 2502-1982 
and a steady-state value of $69.55 \mathrm{~cm}$ with a standard deviation of $\pm 1.775 \mathrm{~cm}$. These result show that fuzzy logic provide a better accuracy in determining stability on quadcopter.

Keywords: UAV, Quadcopter, Stabilize, Fuzzy Logic, Tsukamoto.

\section{Pendahuluan}

Unmanned Aerial Vehicle (UAV) atau pesawat tanpa awak saat ini mengalami perkembangan yang pesat untuk keperluan umum atau keperluan militer. $U A V$ mempunyai beragam jenis diantaranya adalah quadcopter. Quadcopter memiliki kemampuan untuk melakukan pendaratan dan lepas landas secara vertikal atau bisa di sebut dengan Vertical Take-Off and Landing (VTOL). Dalam proses membuat quadcopter ditemukan beberapa permasalahan antara lain seperti keempat baling-balingnya yang tidak mempunyai daya angkat, karena 2 motor masih dirancang berputar secara counterclockwise $(\mathrm{CCW})$ dan 2 motor dirancang berputar Counter Wise $(\mathrm{CW})$, khususnya ketika terbang stabil membawa beban.

Pengendalian kestabilan ketinggian pada penerbangan quadrotor dengan metode PID Fuzzy pernah dilakukan oleh P.A Kusuma tahun 2017[1]. Penelitian P.A Kusuma menunjukan metode kendali PID fuzzy menghasilkan tanggap waktu yang lebih baik dibandingkan dengan metode PID. Penelitian serupa tentang pengendalian kestabilan terbang robot penjelajah udara dengan metode hybrid PID fuzzy juga pernah dilakukan oleh Nur yanti tahun 2018[2]. Penelitian Nuryanti menunjukan bahwa penggunaan hibrid PID-fuzzy mampu mengatasi berbagai masalah kendali saat terbang dengan mengubah nilai gain $K p, K i$, dan $K d$, sehingga dihasilkan kestabilan terbang robot yang baik sesuai dengan ketinggian. Kemudian Ardy Seto Priambodo melakukan penelitian tentang perancangan sistem kendali PD untuk kestabilan terbang melayang UAV Quadcopter[3]. Penelitian yang dilakukannya membahas tentang model sebuah quadcopter dan sistem kendali linier yang bekerja pada quadcopter terbang melayang sehingga quadcopter tersebut mampu terbang dengan stabil. Pada penelitian tersebut sistem kendali linier yang digunakan adalah Sistem kendali $P D$. Sistem ini disimulasikan dengan menggunakan software matlab sehingga di peroleh hasil nilai parameter $K p$ dan $K d$ yang didapatkan dari penelitian tersebut adalah $K p=25$ dan $K d$ $=35$ sedangkan settling time adalah 4,66 detik tanpa overshoot, sehingga hasil respon dinyatakan baik.

Dari [1] dan [2], dapat dianalisis bahwa dengan menggunakan nilai algoritma non-linier seperti logika fuzzy, lebih baik untuk diimplementasikan pada quadcopter dibanding dengan nilai algoritma yang linear seperti arduino. Hal ini disebabkan karena quadcopter mempunyai dinamika non-linier sehingga nilai algoritma yang bersifat non-linier lebih tepat diimplementasikan. Pada penelitian yang dilakukan, variabel yang dikaitkan bukan tentang ketinggian dan perubahan ketinggian tetapi membahas tentang percepatan dan perubahan percepatan motor. Penelitian dilakukan untuk mengatur kecepatan putaran motor agar menjaga kestabilan dan keseimbangan pada waktu take-off serta dapat menjaga kestabilan pada ketinggian tertentu, karena penyebab dari tidak stabilnya quadcopter ketika berada di ketinggian yang ditetapkan adalah adanya perubahan kecepatan.

\section{Metode Penelitian}

\subsection{Analisis Sistem}

Metode penelitian pada Analisis sistem yang akan dibuat adalah untuk mengatur kecepatan putaran motor pada quadcopter agar dapat menjaga kestabilan pada waktu membawa beban dengan menggunakan algoritma fuzzy Tsukamoto. Sebelumnya seperti yang diketahui algoritma fuzzy ada 3 yaitu algoritma Tsukamoto, mamdani dan sugeno. Tetapi pada penelitian ini menggunakan metode Tsukamoto[4]. Penelitian ini menggunakan blok sistem seperti pada Gambar 1. 


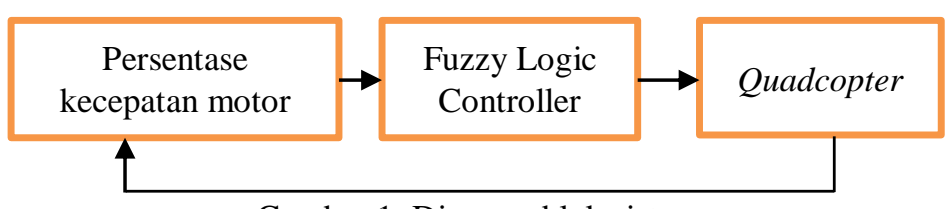

Gambar 1. Diagram blok sistem.

Quadcopter yang digunakan juga menggunakan logika fuzzy untuk memaksimalkan nilai konstanta Arduino. Logika fuzzy akan bertugas sebagai penalar otomatis konstanta arduino yang digunakan untuk mengontrol kestabilan pada Quadcopter digunakan sistem berdasarkan umpan balik berupa nilai error dan delta error. Sistem ini mempunyai nilai konfigurasi (+) yang mengarahkan gerak roll dan pitch-nya dengan dipengaruhi oleh 2 motor yang dirangkai secara seimbang dan simetris. Drone yang akan dibuat mempunyai 4 motor dengan memanfaatkan nilai konfigurasi (+) secara seimbang dan simetris. Kemudian untuk mengetahui nilai ketinggian jarak dapat dengan menggunakan sensor ketinggian yang terpasang pada drone maka dapat dipasang sensor ultrasonik yang terletak tegak lurus dengan sumbu horizontal drone ini. Sensor ultrasonik yang digunakan yaitu sensor ultrasonik tipe HC-SRF04[5]. Cara sensor ultrasonic membaca jarak ketinggian diperlihatkan seperti pada Gambar 2.
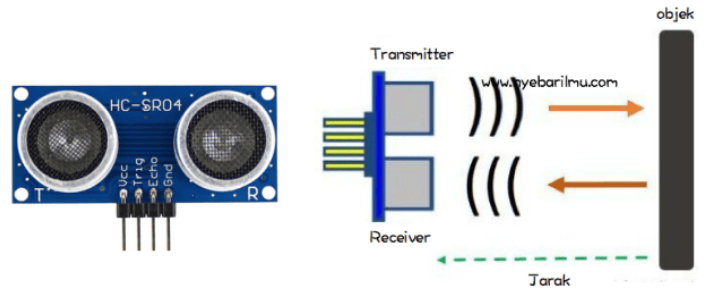

Gambar 2. Sensor ultrasonik HC-SRF04 ketika membaca jarak ketinggian.

Sensor ultrasonik ini memiliki tingkat akurasi sensor yang paling optimal dengan nilai rentang 17 hingga $200 \mathrm{~cm}$. Metode kendali percepatan motor dengan menggunakan arduino. Penalaran yang akan dilakukan untuk mendapatkan nilai konstanta arduino yang akan mempengaruhi karakteristik sistem seperti rise time, settling time, overshoot, dan steady state error. Untuk memperoleh nilai konstanta arduino dapat dilaksanakan dengan penggunaan metode teori Ziegler-Nichols[6]. Teori Ziegler-Nichols bisa diimplementasikan pada sistem seperti pada drone quadcopter tanpa memerlukan model matematikanya. Nilai yang dihasilkan pada gain dapat menghasilkan nilai tanggapan yang kurang baik sehingga membutuhkan fine tuning untuk mendapatkan nilai tanggapan sistem yang sesuai dengan apa yang diharapkan. Kekurangan pada metode ini adalah karena arduino bekerja optimal pada sistem yang berpatokan pada persamaan nilai matematis, sedangkan quadcopter adalah sistem non-linier. Ketidaklinieran sistem quadcopter dapat disebabkan hal-hal seperti karakter motor yang kita pakai, baterai yang digunakan, dan lain sebagainya.

Untuk mengatasi permasalahan tersebut maka pada penelitian ini, dengan mengimplementasikan sistem fuzzy logic dengan kendali arduino dapat membantu, meminimalkan dan mengatasi nilai ketidaklinieran sistem dengan memanfaatkan logika fuzzy. Logika fuzzy adalah metode komputasi dengan variabel kata-kata yang dikemukakan oleh $D r$. Lotfi A. Zadeh pada tahun 1965. Logika ini memanfaatkan menggunakan pendekatan alamiah seperti penalaran manusia dalam menentukan suatu keputusan. Logika fuzzy dapat digunakan untuk memaksimalkan nilai respon dari sistem kendali pada Arduino[7]. Aturan fuzzy untuk memaksimalkan kerja sistem dengan nilai dasar sebagai berikut;

1. Apabila steady-state memiliki nilai besar maka naikkan konstanta proporsional.

2. Apabila respon berosilasi maka naikan konstanta derivative. 
3. Apabila respon lambat maka naikan konstanta proporsional.

4. Apabila steady-state error terlalu besar maka sesuaikan konstanta integral.

5. Apabila overshoot menghasilkan nilai yang terlalu besar maka turunkan nilai konstanta proporsional.

Aturan fuzzy yang dibuat dan diproses dengan memanfaatkan sudut dan nilai ketinggian quadcopter. Berdasarkan nilai hasil set point yang dihasilkan oleh sudut dan ketinggian yang telah ditetapkan maka akan didapat hasil nilai error dan delta error yang merupakan indikator keadaan quadcopter. Berdasarkan uraian di atas maka dapat dirumuskan pokok-pokok sistem yang digunakan dalam penelitian ini yaitu sebagai berikut:

1. Sistem kestabilan yang diterapkan untuk membantu quadcopter untuk mempertahankan kestabilan dan ketinggiannya dengan baik berdasarkan jarak dengan permukaan tanah dengan nilai steady-state error maksimum sebesar $5 \mathrm{~cm}$. Kendali tersebut juga harus mempertahankan steady state error sudut roll dan pitch sebesar 5\% agar pembacaan sensor ultrasonik masih dapat bekerja dengan baik.

2. Risetime yang diperoleh akan di gunakan pada sudut pitch dan roll lebih cepat atau sama dengan 0,5 detik dan pada sudut yaw menghasilkan ketinggian lebih cepat dari 3 detik.

3. Settling time yang diperoleh menghasilkan sudut pitch dan roll sebesar 3 detik, dan nilai sudut yaw serta altitude sebesar 6 detik.

4. Maximum pada nilai overshoot pitch dan roll adalah $10 \%$, dan nilai yaw serta altitude memiliki $20 \%$.

5. Metode kendali yang digunakan dioptimalkan dengan logika fuzzy yang dapat menalar secara mandiri nilai kontstanta $\mathrm{Kp}, \mathrm{Ki}$, dan $\mathrm{Kd}$ pada arduino sehingga respon sistem lebih baik.

\subsection{Rancangan Arsitektur System}

Rancangan arsitektur dari sistem quadcopter yang dirancang diperlihatkan seperti pada Gambar 3.
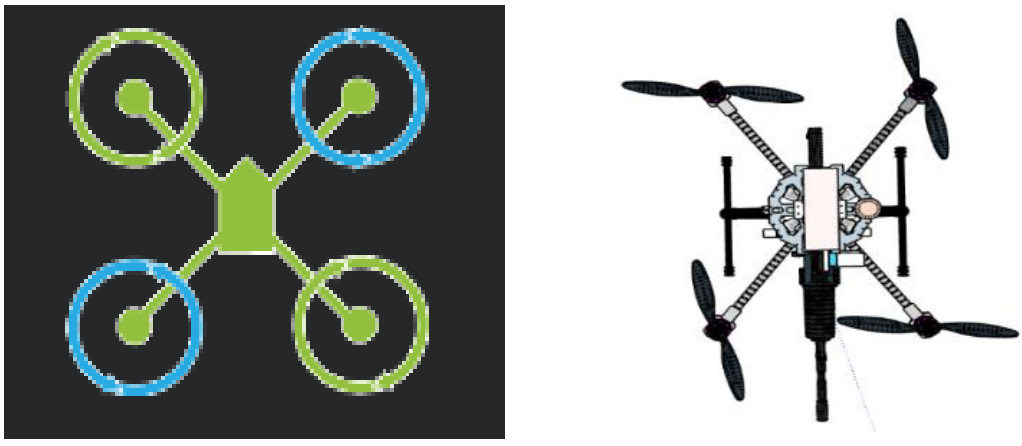

Gambar 3. Rancangan arsitektur system quadcopter.

Dalam penelitian ini pixhawk bertugas sebagai pemroses masukan dan keluaran sistem. Pixhawk digunakan karena memiliki bit penyimpanan yang cukup besar serta mampu bekerja dengan clock yang tinggi agar metode fuzzy yang digunakan dapat berjalan dengan baik. Pada pixhawk Mempunyai 3 buah sensor yaitu IMU 6 DOF[8] yang terdiri dari Accelerometer dan Gyroscope yang memiliki fungsi untuk memberikan masukan pada kondisi ketika drone bergerak secara pitch dan roll. Selain itu ada ada magnometer atau kompas yang digunakan sebagai penunjuk arah atau heading, serta memiliki sensor ultrasonik yang digunakan untuk menunjukan nilai besaran ketinggian quadcopter terhadap permukaan tanah. Sistem kendali dan pemantuan data menggunakan Remote Control (RC) dan GCS berupa sebuah komputer yang terhubung dengan drone quadcopter memanfaatkan modul telemetri. Daya yang diperoleh sistem ini adalah baterai $\mathrm{LiPo}[9]$. 


\subsection{Rancangan Fungsi keanggotaan Fuzzy}

Fungsi keanggotaan fuzzy adalah suatu kurva yang menunjukan pemetaan titik input ke dalam derajat keanggotaan yang nilainya 0 hingga 1 . Salah satu cara yang dapat digunakan adalah dengan melakukan pendekatan fungsi keanggotaan fuzzy. Penelitian ini menggunakan Fuzzy Logic Tsukamoto dengan mengambil nilai rerata $(Z)$ dan dituangkan dalam persamaan,

$$
Z=\frac{\alpha_{1} * \mathrm{z}_{1}+\alpha_{2} * \mathrm{z}_{2}+\ldots \ldots+\alpha_{\mathrm{n}} * \mathrm{z}_{\mathrm{n}}}{\alpha_{1}+\alpha_{2}+\cdots+\alpha_{\mathrm{n}}}
$$

dimana $\alpha_{n}$ adalah derajat keanggotaan dari aturan ke-n dan $z_{n}=$ nilai dari aturan ke-n.

Kemudian hasilnya akan disimulasikan dengan perhitungan Matlab yang menghasilkan kurva seperti Gambar 4.

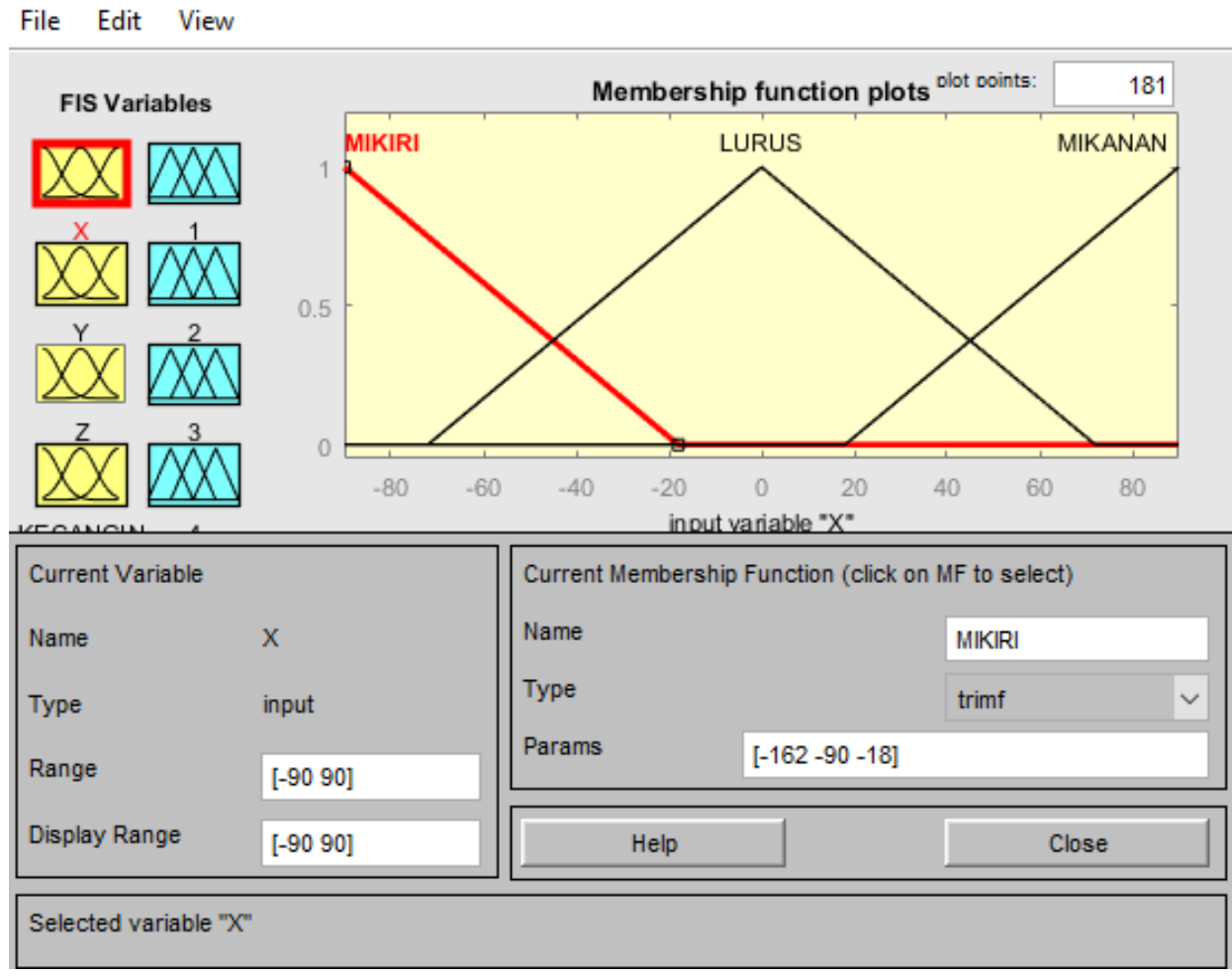

Gambar 4. Kurva fungsi keanggotaan fuzzy.

\subsection{Rancangan Sistem Kendali Kestabilan}

Pada penelitian ini dapat di masukkan tambahan untuk sistem quadcopter yang berupa sensor ketinggian. Dengan sensor ini, kendali untuk ketinggian yang stabil dapat dihitung dengan cara menghitung selisih nilai ketinggian dengan nilai setpoint ketinggian yang diinginkan. Kendali seperti ini untuk mendapatkan kestabilan yang optimal sehingga pilot atau operator tidak perlu mengatur throttle. Logika fuzzy pada rancangan sistem kendali kestabilan ini akan menghitung nilai konstanta proporsional $(K p)$, integral $(K i)$, dan derivatif $(K d)$ terbaik yang bisa di masukkan nilainya untuk memperbaiki nilai sistem. Logika fuzzy ini di gunakan untuk mengatur besaran nilai persentase kecepatan motor dan untuk kendali motor menggunakan Arduino, seperti diperlihatkan pada Gambar 5. 


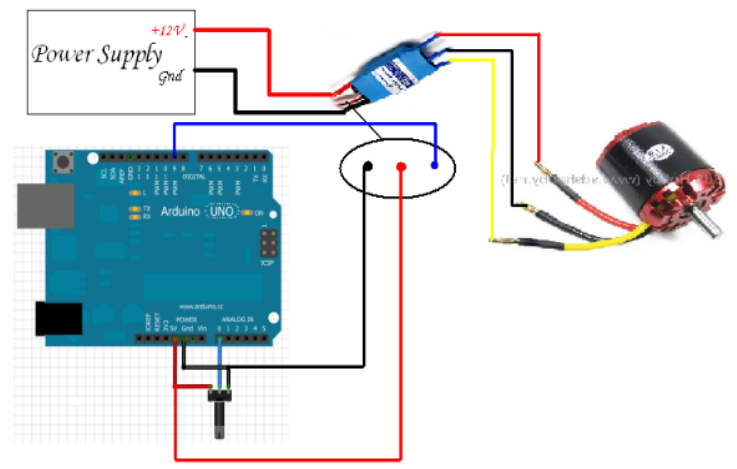

Gambar 5. Diagram kerja Arduino motor menggunakan software Arduino.

Dan sketch pemrograman untuk mengatur kecepatannya dibuat menggunakan Arduino IDE seperti pada Gambar 6.

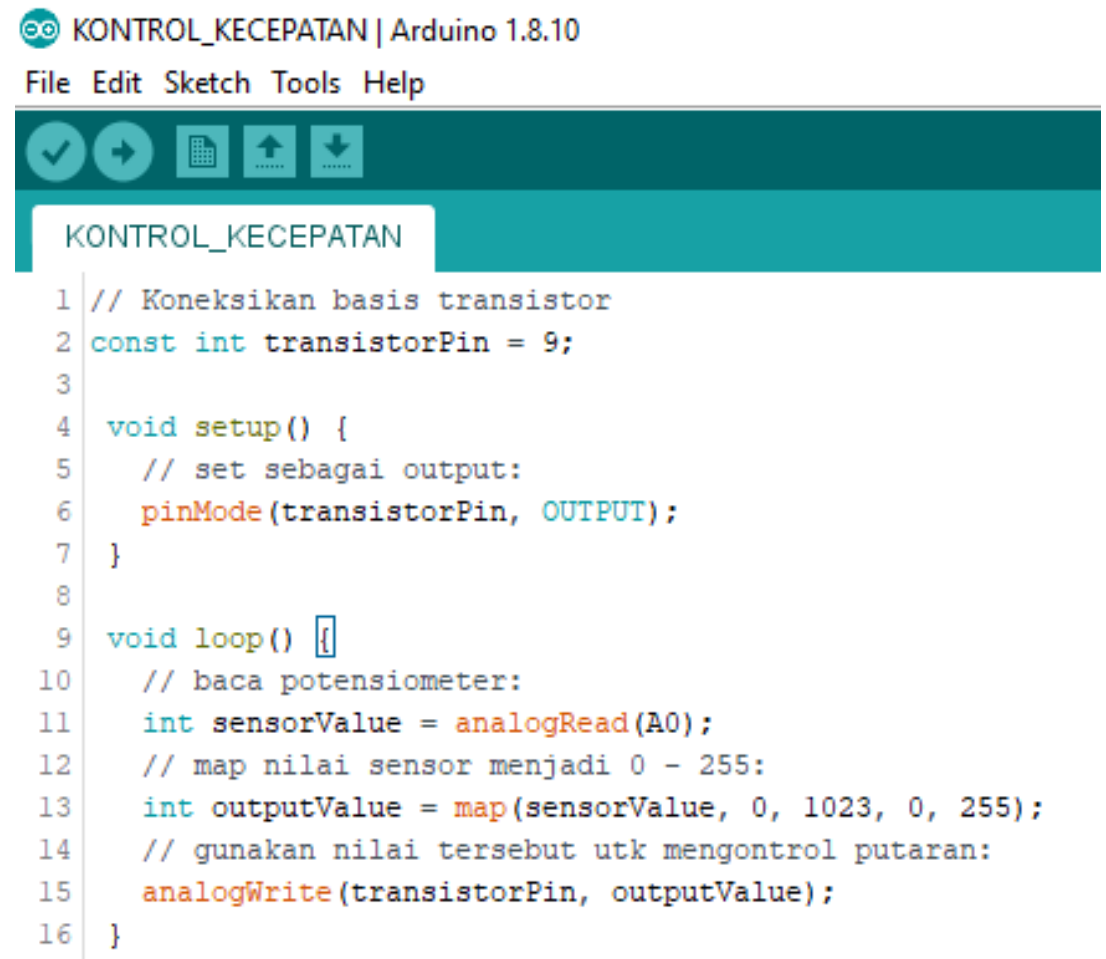

Gambar 6. Sketch arduino untuk mengatur kecepatan.

Dari bahasa pemrograman arduino yang di terapkan maka akan mendapatkan variabel variabel linguistik yang digunakan pada pitch dan roll yaitu NB (Negatif Besar), N (Negatif), O (Nol), P (Postif) dan PB (Positif Besar) untuk memasukkan nilai error yang disebut dengan himpunan fuzzy error. Kemudian untuk memasukkan delta error menggunakan DNB (Delta Negatif Besar), DN (Delta Negatif), DO (Delta Nol), DP (Delta Positif) dan DPB (Delta Positif Besar) yang disebut dengan himpunan fuzzy delta error. Pada setiap variabel diatas akan mempunyai nilai rentan masing masing yang berdasar pada nilai yang didapatkan dari penelitian sebelumnya yang dilakukan oleh program. Kemudian nilai input ini dianalisa oleh Fuzzy Inference system dengan menggunakan aturan fuzzy (rule-base) yang telah disusun. Aturan aturan fuzzy (rule base) memiliki bentuk dasar "if" $\mathrm{X}=\mathrm{A}$, "Then" $\mathrm{Y}=\mathrm{B}$, sehingga aturan fuzzy sering disebut aturan "If-Then". Aturan yang kita buat dengan "if-then" bisa di lihat pada Gambar 7. 


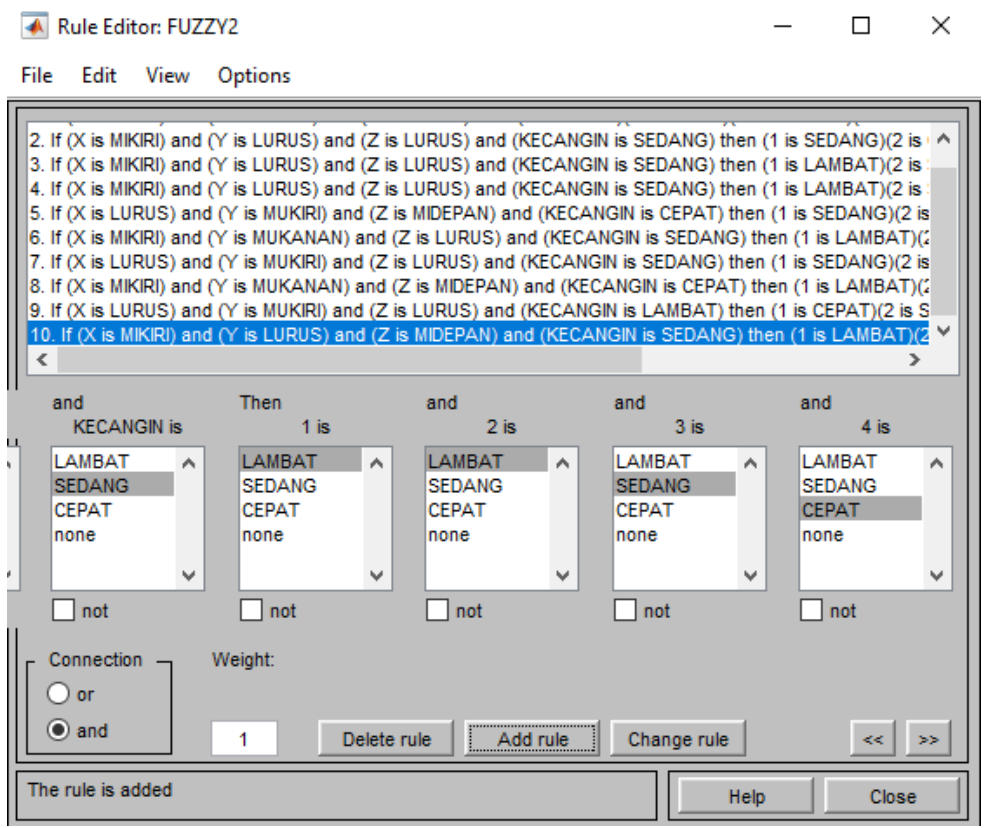

Gambar 7. Rules pada himpunan fuzzy untuk menstabilkan drone quadcopter.

Kemudian pada sistem quadcopter ini aturan fuzzy yang digunakan berdasarkan rancangan himpunan fuzzy untuk nilai error, delta error, Kp, Ki dan Kd. Dengan begitu terdapat 25 aturan fuzzy yang akan digunakan. Aturan dibuat berdasar pada pengaruh perubahan nilai konstanta kecepatan motor yang dikontrol menggunakan Arduino Uno dan derivatif terhadap nilai error dan data error. Aturan untuk $K p$ dan $K i$ dibuat sama karena memang dampak kedua kendali terhadap nilai yang di hasilkan sama. Nilai error dari data error dapat dilihat pada Tabel 1.

Tabel 1. Menunjukkan nilai error.

\begin{tabular}{|c|c|c|c|c|c|c|}
\hline & \multicolumn{6}{|c|}{ Error } \\
\hline & & NS & $\mathrm{N}$ & $\mathrm{O}$ & $\mathrm{P}$ & SP \\
\hline Data & DNS & $\mathrm{T}$ & M & $\mathrm{S}$ & $S$ & $\mathrm{~S}$ \\
\hline error & DN & M & S & B & B & $\mathrm{T}$ \\
\hline & DO & S & B & $\mathrm{H}$ & M & $\mathrm{M}$ \\
\hline & DP & $\mathrm{T}$ & $S$ & B & M & $S$ \\
\hline & DPS & $\mathrm{S}$ & M & M & $\mathrm{S}$ & $\mathrm{T}$ \\
\hline
\end{tabular}

Keterangan:

$\begin{array}{llll}\mathrm{NB} & \text { : Negatif Besar } & \mathrm{P} & \text { : Positif } \\ \mathrm{T} & \text { : Sangat Kecil } & \mathrm{B} & \text { : Besar } \\ \mathrm{N} & \text { : Negatif } & \mathrm{PB} & \text { : Positif Besar } \\ \mathrm{S} & \text { : Kecil } & \mathrm{H} & \text { : Sangat Besar } \\ \mathrm{O} & \text { : Tengah } & & \\ \mathrm{M} & \text { : Sedang } & & \end{array}$

Nilai negatif dan positif pada error dan deltaerror akan menghasilkan nilai Kp dan Ki yang sama, kemudian akan di gunakan karena hal tersebut akan tergantung pada orientasi quadcopter. Jika nilai error besar (NB dan PB) maka nilai $K p$ dan $K i$ yang digunakan yang paling besar (H). nilai delta error yang terbaca akan menunjukan kecepatan respon sistem. 


\subsection{Rancangan Pergerakan UAV}

Drone S2GA ini merupakan drone yang di gerakkan dengan menggunakan 4 buah motor[10]. Empat motor tersebut ditempatkan pada ke empat sisinya dan saling berhadapan antar motornya. Kemudian tiap motor berputar dengan arah masing masing yang berbeda. Sepasang motor berputar searah dengan jarum jam dan 2 pasang lagi berlawanan dengan arah jarum jam. Kemudian dengan mengubah besaran kecepatan putar dari masing masing motor tersebut, kita akan mendapatkan daya angkat yang berbeda beda yang mempengaruhi elevasi, arah terbang dan manuver dari Quadcopter[3]. Bentuk dan arah pergerakan perputaran dari motor dapat dilihat seperti pada Gambar 8.

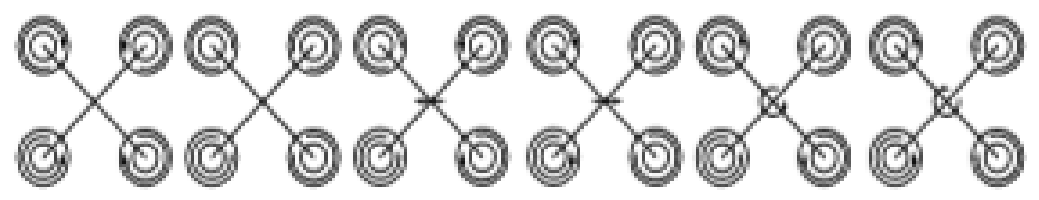

(a)keatas, (b)kebawah, (c)kekiri, (d)kekanan, (e)berputar kekiri, (f)berputar kekanan.

Gambar 8. Bentuk dan arah pergerakan perputaran motor.

\section{Hasil dan Pembahasan}

Pada Penelitian sistem kendali kestabilan ini dilakukan pada sudut pitch dan roll, yang dilakukan dengan memberikan gangguan sebesar kurang lebih $45 \mathrm{~cm}$ dari set point ketinggian sebesar $200 \mathrm{~cm}$. kemudian Risetime atau watu yang dibutuhkan untuk kembali ke posisi semula yaitu sebesar 0,7 detik, settling time sebesar 2,55 detik, dan dengan overshoot sebesar $6,5 \mathrm{~cm}$ atau $15 \%$ dari total gangguan. Sementara pengujian tanpa gangguan didapatkan nilai pembacaan ratarata nilai steady state sebesar $69,55 \mathrm{~cm}$ dengan simpangan baku sebesar $\pm 1,775 \mathrm{~cm}$. Nilai rentang yang dihasilkan dari logika fuzzy logic kestabilan yang digunakan pada pengujian ini dapat di lihat pada Tabel 2 rentang nilai konstanta ketinggian.

Tabel 2. Nilai konstanta.

\begin{tabular}{cccc}
\hline Konstanta & Nilai Min & Nilai tengah & Nilai Max \\
\hline Kp & 0,110 & 0,113 & 0,113 \\
Ki & 0,019 & 0,023 & 0,024 \\
Kd & 0,029 & 0,032 & 0,035 \\
\hline
\end{tabular}

Hasil dari nilai konstanta arduino yang di hasilkan oleh logika fuzzy akan terlihat pada perubahan nilai konstanta yang awal gangguan hingga tidak terjadi gangguan. Kemudian hasil dari himpunan fuzzy yang di hitung dengan menggunakan matlab menghasilkan grafik seperti pada Gambar 9.

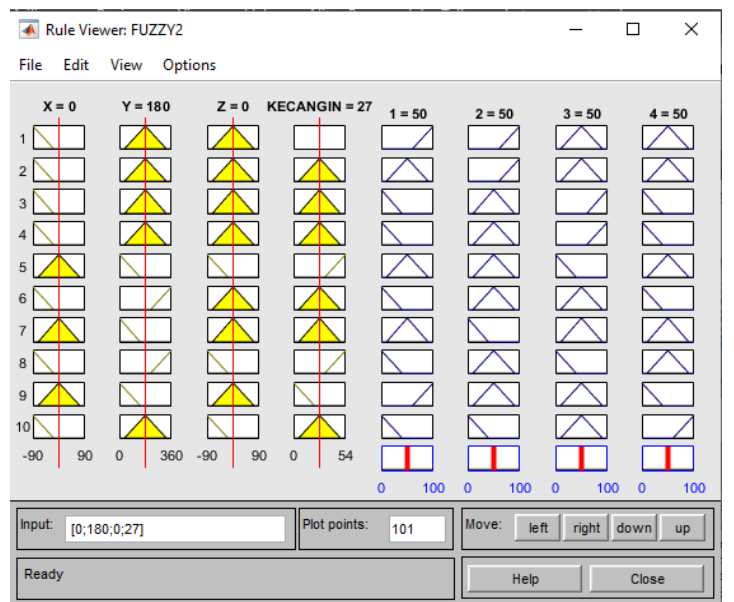

Gambar 9. Hasil rules fuzzy untuk himpunan untuk kestabilan.

ISSN (e): 2540-9123

ISSN (p): 2502-1982 


\section{Kesimpulan}

Dari hasil metode penelitian dapat diperoleh kesimpulan untuk menstabilkan drone quadcopter ini adalah mengatur kecepatan motor penggerak yang di hasilkan. Dengan menggunakan fuzzy logic tsukamoto yang memiliki tingkat akurasi untuk menentukan kestabilan drone quadcopter dengan mengontrol kecepatan keempat motor penggerak. Nilai yang dihasilkan oleh logika fuzzy tsukamoto tersebut lebih mendekati hasil yang lebih baik dalam mengontrol kestabilan quadcopter. Kestabilan ini cenderung untuk mempertahankan posisi tertentu ketika drone ini mengalami gangguan, sehingga drone ini akan menstabilkan dengan menggunakan logika fuzzy tersebut.

\section{Ucapan Terima Kasih}

Saya mengucapkan terimakasih kepada tim telka yang telah menyelengarakan dan membuat template ini kemudian saya mengucapkan terimakasih kepada jurusan telekomunikasi militer poltekad yang mendukung penelitian ini.

\section{Referensi}

[1] P. A. Kusuma and A. Dharmawan, "Pengendalian Kestabilan Ketinggian pada Penerbangan Quadrotor dengan Metode PID Fuzzy," IJEIS (Indonesian J. Electron. Instrum. Syst., vol. 7, no. 1, p. 61, 2017, doi: 10.22146/ijeis.15456.

[2] N. Yanti and F. Z. Rachman, "Pengendalian Kestabilan Terbang Robot Penjelajah Udara Dengan Metode Hybrid Pid-Fuzzy Stability Control Flying the Air Conditioning Robot With Hybrid Pid-Fuzzy Method," vol. 5, no. 6, pp. 705-710, 2018, doi: 10.25126/jtiik51134.

[3] A. S. Priambodo, A. I. Cahyadi, and S. Herdjunanto, "Perancangan Sistem Kendali PD untuk Kestabilan Terbang Melayang UAV Quadcopter," no. July 2017, pp. 117-121, 2019.

[4] S. Lukas, A. Aribowo, and Y. S. Tjia, "Simulasi Kecepatan Kendaraan Dengan Menggunakan Logika Fuzzy," SNATI, 2008.

[5] Y. M. Arif et al., "Implementation Of Ultrasonic Sensor And Fuzzy Logic On Safety And Control Drone System ( QUADCOPTER )," vol. 8, no. 1, pp. 454-460, 2018.

[6] Z. Jamal, "Implementasi Kendali Pid Penalaan Ziegler-Nichols Menggunakan Mikrokontroler," J. Inform., vol. 15, no. 1, pp. 81-88, 2015, doi: 10.30873/ji.v15i1.410.

[7] R. Maulana, F. M. Ula, and G. E. Setyawan, "Sistem Kendali Take-Off Quadcopter Ar.Drone Menggunakan Logika Fuzzy,” J. Pengemb. Teknol. Inf. dan Ilmu Komput. Univ. Brawijaya, vol. 2, no. 9, pp. 3060-3066, 2018.

[8] S. Lins, M. Garratt, A. Lambert, and P. Li, "6DoF Motion estimation for UAV landing on a moving shipdeck using real-Time on-board vision," Australas. Conf. Robot. Autom. ACRA, 2015.

[9] M. Thowil Afif and I. Ayu Putri Pratiwi, “Analisis Perbandingan Baterai Lithium-Ion, Lithium-Polymer, Lead Acid dan Nickel-Metal Hydride pada Penggunaan Mobil Listrik Review," J. Rekayasa Mesin, vol. 6, no. 2, pp. 95-99, 2015, doi: 10.21776/ub.jrm.2015.006.02.1.

[10] A. Hendriawan, G. P. Utomo, and H. Oktavianto, "Sistem Kontrol Altitude Pada UAV Model Quadcopter Dengan Metode PID," 14th Ind. Electron. Semin. 2102 (IES 2012), vol. 2012, no. Ies, pp. 12-16, 2012. 